\title{
Research on Service Innovation of Library in Big Data Age Zhaoyan Deng
}

\author{
Liupanshui Normal University, Liupanshui, Guizhou Province, China, 553004
}

\author{
Keywords: Service Innovation, Library, Big Data Age
}

\begin{abstract}
With the rapid development of cloud computing, networking and information acquisition and storage technology, data is growing and accumulating at a geometric progression rate. At present, the world has entered the "big data" era. Through the analysis of the concept and characteristics of large data, the influence and challenge of big data to the university library, this paper puts forward the strategy of university library service innovation in the era of large data.
\end{abstract}

\section{Introduction}

With the increasing development of cloud computing technology to promote the emergence of large data concepts, large data in the number of very large, a wide range of information, the actual spread of very fast. The development of information technology makes the library readers in the demand, in the scientific environment and other aspects have undergone tremendous changes, access to information is also constantly changing. With the changing of people's value concept, people also have higher requirements and new requirements for library services. The traditional service concept and service mode cannot realize the demand of large data development. This will change the traditional service concept and service mode to achieve the concept and the way of effective innovation for the reader to provide more quality services.

\section{The Overview of Large Data Age}

Large data is in a wide variety of large amounts of data in the rapid access to information, it is not quantitative description of the size of the data size of the term, generally generated in the mail, video, micro-blogging, post and page click, is structured data, half the sum of structured data and unstructured data. The concept of large data first comes from the astronomy and genetics disciplines, and finally widely used, the computer age of the growing information, applied to all walks of life, to play the value of their own information. Large data with four characteristics, namely: the type of large, fast, large capacity and value, take the keyword English first letter, with $4 \mathrm{~V}$ characteristics. These characteristics indicate that large data will bring great changes to the IT industry, so that the form of information and valuable data through a certain technical means, into the data processing, in-depth analysis and value mining information business development process. With the powerful data technology brought about by the growth of data, the data is everywhere, the world really into the era of large data, the rest of the world governments have begun to focus on large data of the core scientific and technical issues, and promote the construction and development of large data disciplines. As a library of information storage and use, the information resources of the library are faced with great challenges, which means that the library should increase the integration of multi-source data and establish the association between multi-source data, according to the above objectives, but also innovative library service model, so that it is based on the data to achieve intelligent goals. Secondly, through the technical means of large data, we can understand and explore the information of the users who use the library to explore the potential information, study the interest of the readers, and then develop new information resources which meet the characteristics of the times.

\section{The Existing Problems in the Library Services}

The Service Concept Is Lagging Behind. In the library service process, adhere to the book as the 
core of the tradition, which makes the library activities are mostly concentrated in the collection of books, book catalog or book circulation, and did not recognize the reader's important role in the library, In the service process has been in a passive position. Large-scale data environment makes people's ideas and understanding of constant changes, and this book-based service concept has been unable to adapt to the actual development needs, library services and modern technology there is a phase out of the phenomenon, the actual service work Unable to meet the actual needs of readers.

Service Mode Is Backward. The traditional library services are mainly borrowed and borrowed from the two aspects of the content, the library in the actual opening hours and the loan period, service methods are normative, but the reader needs and library resources, library services are There is a certain gap. In the provisions of the opening time, the reader relative angle, but the limited service staff makes the actual quality of service is lack of protection. The lagging existence of the library information update makes the gap between the library and the readers' needs. The demand for the library service and the information development is not adaptable. The actual service mode is backward, and the service quality is not Very ideal.

The Overall Quality of Service Staff Is Not High. In the traditional management process, the management staff are responsible for most of the literature editing, literature, things and readers of information services and other aspects of the work cannot meet the reader in the reading needs of the satisfaction of the actual service is not very ideal, The reason is mainly due to the overall quality of the library management staff is not high, most of the library service staff lack of network information technology, literature collation and collection of most of the traditional way, the work efficiency is not high, for the reader demand information The requirements of grasp there is also lagging behind, the actual efficiency of the service is not very ideal.

\section{The Opportunities and Challenges Brought by the Big Data to the University Library}

Nowadays, people's understanding of large data is more and more in-depth, dealing with large data, analysis of large data technology is also getting higher and higher and the value of large data is also growing. The era of large data brings opportunities and challenges for the development of university libraries, requiring the library to keep abreast of its service requirements, not only to analyze a large number of structured data, but also to analyze a large number of semi-structured and unstructured data to Speculate on the current information needs of readers, and can predict the future needs of readers.

Support for Large Data Is Needed to Improve the Quality of Library Services. Compared with the previous library collections, construction equipment, circulation of borrowing services and other aspects of competition, large data age library competition between the cores will have a large amount of data, digging large data and the ability to analyze large data. University library as a school for scientific research, teaching service information center, but also to make full use of large data thinking and large data technology, found the potential value of information for teachers and students to provide efficient and intelligent services. At the same time, the development and implementation of the strategy of the development of university libraries also need comprehensive support for large data.

Large Data Bring A Lot of Problems to the University Library Digital Resources. With the development and rapid development of business database such as China Knowledge Network, Weipu, Wanfang and Superstar, the number and quantity of digital resources in university library have increased dramatically. Which has brought many problems to the construction of library digital resources, such as the increasing of data repetition, the lack of investment in digital resources construction of university libraries, the lack of characteristics of digital resource allocation, the serious homogeneity, the construction of digital resources The shortage of talent, the construction of digital resources standards and services and other aspects of the problem is more prominent.

Big Data Brings Pressure and Challenge to Traditional Libraries. With the rapid development of digital information technology, online bookstore, online virtual database and a variety of free online library filled with the Internet, making the traditional library readers become increasingly serious, so as to the development of traditional university library brought pressure and 
challenge. To meet the challenges, in the pressure to move forward, we must open up new ideas, the university library can use large data technology for the needs of readers to analyze the data, according to the results of targeted research services to attract readers.

\section{The Innovation Strategy of University Library's Service in the Big Data Age}

Enhance the Quality of Librarians and Innovative Service Level. In the era of large data, it puts forward higher requirements for the technology and ability of people to deal with the data. For the university library, it is necessary to innovate the service level of the library, first of all, to improve the quality of librarians and improve their professional level and occupation Spirit, for the librarians to create a lifelong learning atmosphere. You can take to strengthen the job training, in-service training, interlibrary exchange, seminars and e-learning and other ways to encourage librarians to improve their business level.

Innovative Service Concept and Advocate People-Oriented Human Services. "People are the starting point and attribution of all the work of the library, but also the basis of the existence and development of the library. People are the library of the service object and work center, but also measure the success or failure of the library work standard. The library will lose the value of survival. "This sentence profoundly illustrates the people-oriented, the meaning of human services. University library to do humane service, bear the brunt of is to optimize the service environment, not only to optimize the material environment of the library, including the layout of the premises, the museum outside the layout of the environment, etc., to the reader as the goal, For the reader to provide convenient, comfortable reading environment. But also to optimize the human environment of the library, the human environment is a hidden intangible environment, can fully reflect the library commitment to human knowledge of the important task of the library in the long process of service formed a subtle attitude, beliefs and other cognitive environment.

Innovative Services to Enhance the Level of Intelligent Library. With the continuous development of various new information technology and the relevant researchers have also launched a variety of suitable for the library of new service technologies, such as the application of things in the library to promote the rapid development of mobile library and so on. In 1999 the United States first proposed the concept of Internet of things, in July 2006 China's Shenzhen Library for the first time the full use of RFID equipment, to achieve the library books self-borrowing, intelligent sorting book car, security monitoring and self-help And a series of intelligent service functions. Not only saves the library manpower cost, more importantly, enhance the quality and efficiency of the service, to bring a lot of convenience to the reader. With the bank ATM function of the same library self-help by the machine has been the major colleges and universities to quickly promote the library, not only can achieve the paper 24 hours by the service, but also provides readers with self-help query and other functions. With the development of wireless communication technology and the popularity of smart phones such as 2G, 3G and even 4G, the introduction of mobile library not only meets the service requirements of readers at any time, consult and download resources, but also allows readers to make full use of life Many of the "fragmented time" to improve the efficiency of learning.

Innovative Book Procurement Technology and Take Books Procurement Based on Data Mining. Procurement is an important part of the work of university library, the quality and quantity of the collection construction is deeply influenced by the level of the book interview. The interview level is directly related to the level of the library providing services for the research and teaching. Today, the chaos of literature publishing and the rising prices of literature, coupled with the limitations of library funding, bring great challenges to library interviewers. In the large data environment, it is possible to analyze and dig the data of the library's OPAC system data, the purchase records of the reader's purchase system and the borrowing records in the borrowing system.

Enhance the Degree of Resources Sharing. Library collection resources should be closely around the school's actual school, and disciplines and professional construction combined for the school teaching and research services. The purchase of resources and self-built digital resources 
should be applied as the goal, therefore, collection of literature resources not only to be targeted, integrity and continuity, but also reflect the characteristics of the school disciplines. At the same time, in the construction of resources to strengthen and other similar university library to build and share, will add more digital resources to share the scope of sharing, for example, in the characteristics of the database planning, topics, standards and other aspects of the museum mutual communication and coordination, disciplines close to or close to the library can be carried out jointly between the construction of the characteristics of the database to make up for the lack of library resources in their respective libraries.

\section{Conclusion}

The development of information technology has led to the continuous expansion of information, the era of large data promotes the library needs to change the traditional service concept, recognizing that it cannot maintain the effective development by their own collection, which requires an effective analysis of the needs of readers, To provide readers with more high-quality, targeted services, and constantly enrich the reader's experience in reading, to achieve effective sharing of knowledge to enhance the quality of library services. The rapid development of digital network has brought great development opportunities for the library.

\section{References}

[1] Hu Lixiang.To the big data knowledge service: large data age library service model innovation [J]. Journal of Library and Information Sciences in Agriculture, 2014 (2), 25-26

[2] Li Xingkun. Service to Big Data Knowledge: Innovation of Library Service Model in Big Data Age [J]. Science and Wealth, 2014 (9), 74-76

[3] Bai Wu Ni Le. The development of large library of library services and its innovation[J]. Science and Technology Outlook, 2015 (14), 144-145

[4] Zhang Shiming. University library digital resources construction status and development strategy[J]. Information Exploration, 2008 (9): 44-46.

[5] Wang Ye Xuan. Large resources in the background of university library resources construction[J]. Journal of Anshan Normal University, 2013 (12), 102-104 